\title{
Epigallocatechin Gallate in Progressive MS
}

\section{A Randomized, Placebo-Controlled Trial}

Rebekka Rust, MD, Claudia Chien, MSc, Michael Scheel, MD, Alexander U. Brandt, MD, Jan Dörr, MD, Jens Wuerfel, MD, Katharina Klumbies, MD, Hanna Zimmermann, PhD, Mario Lorenz, PhD, Klaus-Dieter Wernecke, PhD, Judith Bellmann-Strobl, MD, * and Friedemann Paul, MD*

Neurol Neuroimmunol Neuroinflamm 2021;8:e964. doi:10.1212/NXI.0000000000000964

\section{Abstract}

\section{Objective}

To examine whether treatment with epigallocatechin gallate (EGCG) influences progression of brain atrophy, reduces clinical and further radiologic disease activity markers, and is safe in patients with progressive multiple sclerosis (PMS).

\section{Methods}

We enrolled 61 patients with primary or secondary PMS in a randomized double-blind, parallelgroup, phase II trial on oral EGCG (up to 1,200 mg daily) or placebo for 36 months with an optional open-label EGCG treatment extension (OE) of 12-month duration. The primary end point was the rate of brain atrophy, quantified as brain parenchymal fraction (BPF). The secondary end points were radiologic and clinical disease parameters and safety assessments.

\section{Results}

In our cohort, 30 patients were randomized to EGCG treatment and 31 to placebo. Thirty-eight patients (19 from each group) completed the study. The primary endpoint was not met, as in 36 months the rate of decrease in BPF was $0.0092 \pm 0.0152$ in the treatment group and $-0.0078 \pm$ 0.0159 in placebo-treated patients. None of the secondary MRI and clinical end points revealed group differences. Adverse events of EGCG were mostly mild and occurred with a similar incidence in the placebo group. One patient in the EGCG group had to stop treatment due to elevated aminotransferases ( $>3.5$ times above normal limit).

\section{Conclusions}

In a phase II trial including patients with multiple sclerosis (MS) with progressive disease course, we were unable to demonstrate a treatment effect of EGCG on the primary and secondary radiologic and clinical disease parameters while confirming on overall beneficial safety profile.

\section{Clinicaltrial.gov Identifier NCT00799890.}

\section{Classification of Evidence}

This phase II trial provides Class II evidence that for patients with PMS, EGCG was safe, well tolerated, and did not significantly reduce the rate of brain atrophy.

\author{
Correspondence \\ Prof. Dr. Paul \\ friedemann.paul@charite.de
}

MORE ONLINE

$\rightarrow$ Class of Evidence

Criteria for rating therapeutic and diagnostic studies

NPub.org/coe 


\section{Glossary}

$\mathbf{A A R}=$ annualized atrophy rate; $\mathbf{A E}=$ adverse event; $\mathbf{A R R}=$ annualized relapse rate; $\mathbf{B B B}=$ blood-brain barrier; $\mathbf{B D I}=$ Becks Depression Inventory I; BPF = brain parenchymal fraction; CDP = confirmed disability progression; EAE = experimental autoimmune encephalomyelitis; EDSS = Expanded Disability Status Scale; EGCG = epigallocatechin gallate; FSS = Fatigue Severity Scale; GMV = gray matter volume; GTE = green tea extract; ITT = intention to treat; MFIS = Modified Fatigue Impact Scale; MS = multiple sclerosis; MSFC = MS Functional Composite; OCT $=$ optical coherence tomography; OE $=$ open-label extension; PAS $=$ primary analysis set; PASAT $=$ Paced Auditory Serial Addition Test PBVC $=$ Percentage Brain Volume Change; $\mathbf{P M S}=$ progressive MS; $\mathbf{P P}=$ per protocol; PPMS = primary progressive MS; $\mathbf{R R M S}$ = relapsing-remitting MS; $\mathbf{S A E}=$ serious adverse event; SPMS = secondary progressive MS; TIV = total intracranial volume; WMV = white matter volume.

Safe and effective treatment options with neuroprotective properties for progressive MS (PMS) are an unmet clinical need. ${ }^{1}$ In contrast to many approved therapies for the relapsing course, ${ }^{2,3}$ there are only the monoclonal antibody ocrelizumab ${ }^{4}$ for primary progressive MS (PPMS) and the chemotherapy agent mitoxantrone as well as newly the sphingosine 1-phosphate receptor modulator siponimod ${ }^{5}$ for the treatment of secondary progressive MS (SPMS).

One of the main goals for PMS treatment is to slow progression of neurologic impairment arising from permanent tissue injury ${ }^{1}$ often evaluated by the degree of brain atrophy. ${ }^{6}$

Epigallocatechin-3-gallate (EGCG) is a polyphenolic green tea catechin $^{7}$ with anti-inflammatory and neuroprotective properties demonstrated in animal and ex vivo studies. ${ }^{8,9}$ In experimental autoimmune encephalomyelitis (EAE), an animal model of MS, it was shown to reduce brain inflammation and neuronal damage by influencing $\mathrm{T}$-cell proliferation, inhibiting the activation of nuclear factor- $\mathrm{kB}$ (NF-kB), and exerting antioxidant effects. ${ }^{10-12}$

Its approval as a dietary supplement with a satisfactory longterm safety profile ${ }^{13}$ could make EGCG an attractive treatment for patients with PMS with possible neuroprotective effects.

The present study investigated the effect of EGCG on brain atrophy, further radiologic parameters, and clinical disease activity and safety aspects in patients with PMS during a 36month double-blind treatment period. This study was extended by an optional open-label period (OE) for another 12 months.

\section{Methods}

\section{Primary Research Question}

This monocentric, prospective, phase II, double-blinded, parallel-group, randomized controlled trial was designed to evaluate the question whether the oral intake of up to $1,200 \mathrm{mg}$ EGCG reduces the rate of brain atrophy in patients with PMS and is safe and well tolerated. The study was conducted in Berlin, Germany, from May 2009 to February
2016. The study is rated Class II because less than $80 \%$ of enrolled patients completed the study.

\section{Patients}

Eligibility criteria comprised fulfillment of the 2005 revised McDonald criteria for $\mathrm{MS}^{14}$ and the diagnosis of PPMS or SPMS, age between 18 and 65 years, Expanded Disability Status Scale $(\text { EDSS })^{15}$ score of 3 to 8 at screening, and a relapse-free period of at least 30 days before randomization. No MS disease-modifying therapy was allowed.

Key exclusion criteria were a relapsing-remitting form of MS, a major systemic or CNS disease, especially such as Parkinson, Huntington, or Alzheimer disease as well as clinically relevant predefined laboratory abnormalities (aminotransferases $>3.5$ times above normal limit), and intake of any potentially hepatotoxic medication. Additional consumption of green tea or green tea extract (GTE) was prohibited.

\section{Standard Protocol Approvals, Registrations, and Participant Consents}

The study was approved by the local ethics committees (LaGeSo ZS EK 10 407/08, new: 08/0407-EK 15) and by the German Federal Institute for Drugs and Medical Devices (BfArM). This trial is registered with EudraCT (2008005213-22) and clinicaltrials.gov (NCT00799890). It was conducted according to the Declaration of Helsinki in its applicable version, and every participant provided written informed consent before screening.

\section{Data Availability}

As far as permitted according to data protection requirements and consent provided by the participants, original data are available from the corresponding author on request from any qualified investigator within 5 years after publication.

\section{Randomization and Blinding}

To account for potential baseline data imbalances, patients were stratified before randomization for sex (female and male) and diagnosis (PPMS and SPMS). Patients were randomly (1:1) assigned to receive either Sunphenon/EGCG capsules (GTE containing $>90 \%$ EGCG, product of Taiyo International, taiyointernational.com) or capsules of placebo with identical appearance. 
A block randomization list was generated by the independent pharmacy to assign patients either to EGCG or to placebo for 36 months.

Only the pharmacist was aware of treatment allocation throughout the study; all staff and patients remained blinded to treatment allocation with the exception of 1 patient who was prematurely unblinded by having the study medication analyzed in an external laboratory at his own discretion. This led to the patient's exclusion from the study.

Following the blinded randomized part of the study (until month 36), the patients were offered the opportunity to participate in another 12-month OE, in which all patients received EGCG.

\section{Procedures}

Following randomization, patients started treatment with EGCG or placebo capsules $200 \mathrm{mg}$ daily. Divided into 2 doses, they were escalated after 3 months to $400 \mathrm{mg}$ daily, after 6 months to $600 \mathrm{mg}$ daily, after 18 months to $800 \mathrm{mg}$, and after 30 months to $1,200 \mathrm{mg}$ daily until the end of the study at month 36 .

Patients initially treated with placebo and decided to participate in the 12-month OE started treatment with EGCG capsules $200 \mathrm{mg}$ daily, then escalated every 2 weeks with $200 \mathrm{mg}$, reaching $1,200 \mathrm{mg}$ after 10 weeks. For the patients treated with EGCG, the dosage was maintained during OE, until month 48 if they participated.

Patients received containers with EGCG capsules or placebo sufficient until the next study visit. At each of these visits, drug accountability was performed (number of taken capsules).

Standardized neurologic assessments including $\operatorname{EDSS}^{15}$ and MS Functional Composite (MSFC) $)^{16,17}$ consisting of 9-Hole Peg Test, timed 25-foot walk test, and Paced Auditory Serial Addition Test (PASAT) were performed by a blinded and especially trained examiner at the initial screening (which was at most 1 week before randomization), then every 6 months, and at every unscheduled visit when a relapse was suspected. To avoid any training effect in the PASAT, each participant underwent at least 3 test scorings before study scoring.

At baseline and at month 36, fatigue and depressive symptoms were assessed by the Fatigue Severity Scale (FSS) ${ }^{18}$ and Modified Fatigue Impact Scale (MFIS) $)^{19}$ as well as Becks Depression Inventory I (BDI). ${ }^{20}$ An optical coherence tomography (OCT) was also performed every 12 months.

Safety assessments included reporting of adverse events (AEs), medical examinations, and laboratory examinations. Visits were scheduled every 2-3 months and with short-term follow-up in case of pathologic results.

\section{MRI Data Acquisition and Analysis}

MRI was performed on one 1.5 Tesla scanner (Sonata Siemens, Erlangen, Germany). The MRI protocol included a
$\mathrm{T} 2 \mathrm{w}$ fluid-attenuated inversion recovery sequence $(\mathrm{TR} / \mathrm{TE}=$ $10,000 / 108 \mathrm{~ms}, 0.5 \times 0.5 \times 3 \mathrm{~mm}^{3}$, no gap) and a highresolution 3D T1-weighted sequence (magnetization prepared rapid acquisition gradient echo, MPRAGE: TR/TE = $2110 / 4.38 \mathrm{~ms}, 1 \times 1 \times 1 \mathrm{~mm}^{3}$ ), before and after IV contrast agent administration. Brain parenchymal fraction (BPF), percent brain volume change (PBVC), and T2w hyperintense lesions were quantified at screening and months 12, 24, and 36, whereas contrast-enhancing T1-weighted lesions (CELs) were quantified at screening and month 36 .

Brain atrophy was assessed from lesion infilled MPRAGE images using 2 approaches. BPF was assessed for each time point using the CAT12 software package (version 12.5-neuro.unijena.de/cat/). Here, gray matter volume (GMV) and white matter volume (WMV) and total intracranial volume (TIV) were segmented and visually checked for segmentation errors. $\mathrm{BPF}$ was calculated as follows: $\mathrm{BPF}=(\mathrm{GMV}+\mathrm{WMV}) / \mathrm{TIV}$. Atrophy was then calculated as the difference between baseline and subsequent time points. In an additional approach, the PBVC was quantified longitudinally using the SIENA pipeline (FMRIB software package, FSL Version 5.0.9). ${ }^{21}$

T2w lesion load and CELs were manually segmented using ITK-SNAP. ${ }^{22}$ Lesions were infilled in MPRAGE images using the FSL lesion filling tool (FMRIB software package, FSL Version 5.0.9). ${ }^{21}$

\section{Primary and Secondary Outcomes}

The primary outcome was the change of $\mathrm{BPF}^{23}$ from baseline to month 36. Secondary MRI outcome measures were $\mathrm{PBVC}^{21}$ at month 36, increase (difference from month 36 to baseline) in number and volume of all T2-weighted (T2w) hyperintense lesions, and the number and volume of CELs at month 36 . Secondary outcomes of OCT are reported in detail elsewhere.

Secondary clinical outcome measurements were disability progression as measured by EDSS and confirmed disability progression (CDP) defined as a 1-point increase in the EDSS if the baseline score was 3.0-5.5, or a 0.5-point increase if the baseline score was 6.0 and above, confirmed at a scheduled visit 6 months later. Further secondary clinical outcome parameters were annualized relapse rate (ARR), MSFC, BDI, FSS, and MFIS.

Safety assessments were also part of the secondary outcomes. At the end of the OE, the primary and secondary outcome parameters were assessed again.

\section{Statistical Analysis}

The study was initially planned as a double-blind adaptive pilot study for the inclusion of an initial total of 60 patients with subsequent sample size recalculation. ${ }^{24}$ The latter was not performed due to recruitment difficulties. At the end of the blinded phase (after 36 months), the study was unblinded, resulting in 61 patients altogether (30 randomized to verum 


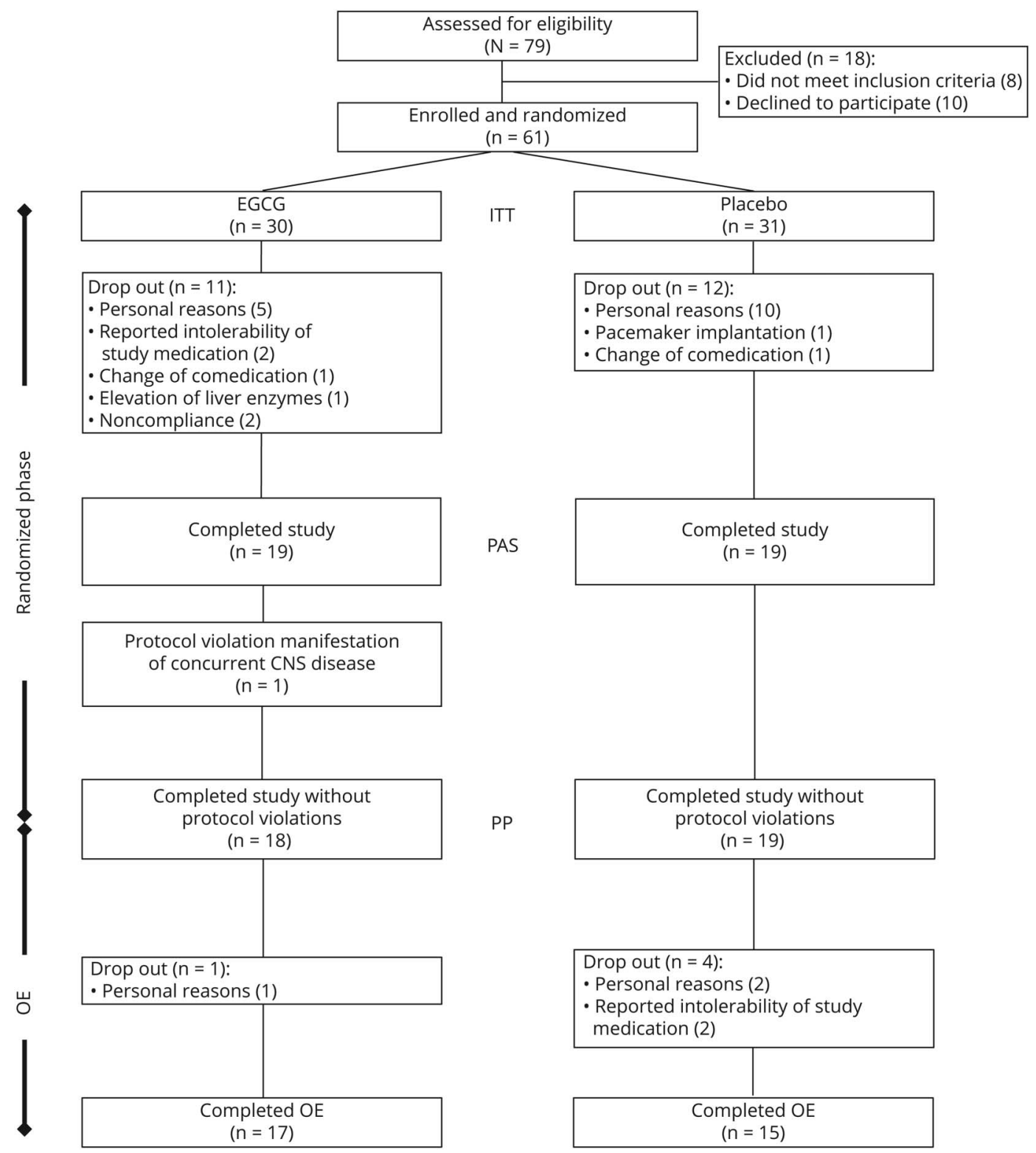

$\mathrm{ITT}=$ intention-to-treat population; $\mathrm{OE}=$ open-label extension; $\mathrm{PAS}=$ primary analysis set; $\mathrm{PP}$ = per-protocol population.

and 31 randomized to placebo) and an OE implemented (compare CONSORT diagram, figure 1).

Results are expressed as arithmetic mean $\pm \mathrm{SD}$, median (range), or frequencies (\%). The primary end point BPF was assessed using the exact Mann-Whitney test.

Continuous secondary endpoints were tested for differences between groups by using the nonparametric (exact) MannWhitney test for independent groups. Differences in categorical variables were tested by the Fisher exact test.

Differences between the verum and placebo group with respect to the whole time course were analyzed using nonparametric analysis of longitudinal data in a 2 -factorial $\operatorname{design}^{25}$ (first factor (independent): treatment groups, second factor (dependent): study visits). This cumulates in 3 tests: differences in groups, significant changes in time, and interactions between groups and time. When appropriate, multivariate, nonparametric analysis of covariance ${ }^{26}$ using baseline values as covariates was complemented.

Because of the large number of missings and lost to follow-up, we abstained from a full data set analysis according to the intention-to-treat (ITT) principle. Instead, we used a modified ITT approach, in which we excluded patients in both groups who dropped out of the study (primary analysis set [PAS], 38 patients). In addition, a per-protocol analysis (PP, 
Table 1 MRI Outcome Parameters After 36 Months (Primary Analysis Set)

\begin{tabular}{|c|c|c|c|}
\hline & EGCG $(n=19)$ & Placebo $(n=19)$ & $p$ Value \\
\hline BPF & $0.6943(0.0502)$ & $0.6867(0.0439)$ & $0.608^{\mathrm{a}}$ \\
\hline Change from baseline & $0.0092(0.0152)$ & $0.0078(0.0159)$ & $0.670^{a}$ \\
\hline Median & $0.7040(0.6000$ to 0.7710$)$ & $0.6840(0.6020$ to 0.7560$)$ & \\
\hline Percent brain volume change & $-0.5659(0.9818)$ & $-0.8013(1.1996)$ & $0.603^{a}$ \\
\hline Median & $-0.5869(-2.3057$ to 0.9561$)$ & $-0.9600(-2.4856$ to 0.9701$)$ & \\
\hline No. of T2w lesions & $35.21(16.84)$ & $39.32(19.28)$ & $0.501^{a}$ \\
\hline Change from baseline & $1.52(4.23)$ & $3.78(4.88)$ & $0.146^{\mathrm{a}}$ \\
\hline Median & 30 (8 to 63 ) & 39 (5 to 76$)$ & \\
\hline Volume of T2w lesions (mL) & $17.57(16.47)$ & $16.90(17.30)$ & $0.773^{\mathrm{a}}$ \\
\hline Change from baseline $(\mathrm{mL})$ & $1.04(1.48)$ & $0.52(2.36)$ & $0.043^{a}$ \\
\hline Median & 11.65 (1.64 to 64.63$)$ & 12.20 (0.91 to 67.98$)$ & \\
\hline No. of CELs ${ }^{b}$ & $0.00(0.00)$ & $0.13(0.34)$ & $0.964^{\mathrm{a}}$ \\
\hline Median & $0(0$ to 0$)$ & $0(0$ to 1$)$ & \\
\hline Volume of CELs $(\mathrm{mL})^{\mathrm{b}}$ & $0.00(0.00)$ & $0.00(0.01)$ & $0.984^{\mathrm{a}}$ \\
\hline Median & 0.00 (0.00 to 0.00$)$ & $0(0.00$ to 0.04$)$ & \\
\hline
\end{tabular}

Abbreviations: $\mathrm{BPF}=$ brain parenchymal fraction; $\mathrm{CEL}$ = contrast-enhancing lesion; $\mathrm{EGCG}=$ epigallocatechin-3-gallate.

Data are mean (SD) or median (range).

a Exact Mann-Whitney test.

${ }^{\mathrm{b}}$ Number and volume of CELs for 18 patients of EGCG and 16 patients of the placebo group.

37 patients) was performed, omitting patients who severely violated study protocol (see CONSORT diagram, figure 1).

A $p$ value $<0.05$ was considered statistically significant. All tests of secondary end points were conducted as exploratory data analysis. Therefore, no adjustments for multiple testing were made.

Numerical calculations were performed using SAS version 9.4 [TS1M3] copyright 2002-2012 by SAS Institute Inc., Cary, NC, IBM SPSS Statistics, Version 25, Copyright 1989, 2010 SPSS Inc., an IBM Company, Chicago, IL. and The R Project for Statistical Computing, Version 3.0.2 (2017-04-21).

\section{Results}

\section{Patients}

Sixty-one participants were randomly assigned to receive either EGCG $(n=30)$ or placebo $(n=31)$ (figure 1). The EGCG and placebo group were similar for all baseline variables (table e-1, links.lww.com/NXI/A420). Thirty-seven percent of patients in the EGCG group and 39\% of those in the placebo group had primary progressive disease; the others had secondary progressive disease. All included patients were of Caucasian ethnicity.

Thirty-eight patients (19 from each group) completed the study and were analyzed for the primary outcome. Twenty- three patients (11 EGCG [36.7\%] and 12 placebo [38.7\%]) withdrew from treatment (figure 1), mainly for personal reasons or change of comedication.

In the EGCG group, 2 patients reported partial intolerability to the study medication (not specified) and discontinued the study (dropout), and 1 patient dropped out due to elevated aminotransferases ( $>3.5$ times above normal limit), which normalized after seizing medication. Reduction of study drug dosage was not required in any other patient.

All participants completing the full 36 months had a compliance of at least $80 \%$ when evaluating intake of study medication.

\section{MRI Outcomes}

The results of the ITT analyses for the MRI outcome parameters are summarized in table 1 . Regarding the primary end point difference BPF (BPF [baseline-month 36]), we observed no difference between groups (EGCG $=0.0092[\mathrm{SD}$ 0.0152 ]; placebo $=0.0078$ [SD 0.0159]; $p=0.670$ ), giving annualized atrophy rates (AARs) of $0.31 \%$ for verum and $0.26 \%$ for the placebo group (difference $0.05 \%$ ).

Regarding secondary end points at month 36 , the EGCG and the placebo group did not differ in PBVC $(p=0.603$, giving AAR of $0.19 \%$ for verum and $0.27 \%$ for placebo 
Table 2 Clinical Outcome Parameters After 36 Months (Primary Analysis Set)

\begin{tabular}{|c|c|c|c|}
\hline & EGCG & Placebo & $p$ Value \\
\hline EDSS & $\mathrm{n}=19$ & $n=20$ & \\
\hline Mean & $6.08(1.07)$ & $5.73(1.12)$ & $0.098^{\mathrm{a}}$ \\
\hline Change from baseline & $0.26(0.45)$ & $0.57(0.99)$ & $0.421^{a}$ \\
\hline Median & $6.5(3.0-8.0)$ & $6.0(3.5-8.0)$ & \\
\hline Annualized relapse rate & $n=19$ & $n=20$ & \\
\hline Mean & $0.24(0.46)$ & $0.19(0.44)$ & $0.513^{a}$ \\
\hline Progression by EDSS & $\mathrm{n}=18$ & $\mathrm{n}=19$ & \\
\hline Number & $6(33.3 \%)$ & $8(42.1 \%)$ & $0.737^{b}$ \\
\hline MS functional composite (z-score) & $n=12$ & $n=15$ & \\
\hline Mean & $0.56(0.45)$ & $0.07(0.75)$ & $0.931^{a}$ \\
\hline Change from baseline & $0.16(0.37)$ & $-0.13(0.38)$ & $0.126^{a}$ \\
\hline Paced Auditory Serial Addition test & $n=17$ & $n=20$ & \\
\hline Mean & 51.35 (10.95) & $42.05(14.90)$ & $0.051^{\mathrm{a}}$ \\
\hline Change from baseline & $3.82(9.65)$ & $1.00(5.79)$ & $0.292^{\mathrm{a}}$ \\
\hline 9-Hole Peg Test in s (average) & $n=16$ & $\mathrm{n}=19$ & \\
\hline Mean & $27.64(11.36)$ & $31.27(8.32)$ & $0.117^{a}$ \\
\hline Change from baseline & $1.48(7.94)$ & $3.00(6.82)$ & $0.172^{\mathrm{a}}$ \\
\hline Timed 25-Foot Walk Test in s (average) & $n=14$ & $n=16$ & \\
\hline Mean & $14.19(10.61)$ & $10.98(8.07)$ & $0.275^{\mathrm{a}}$ \\
\hline Change from baseline & $1.99(9.00)$ & $0.23(5.85)$ & $0.880^{\mathrm{a}}$ \\
\hline FSS & $n=10$ & $\mathrm{n}=11$ & \\
\hline Mean & $4.41(2.07)$ & $4.54(1.76)$ & $0.931^{a}$ \\
\hline Change from baseline & $-0.90(1.86)$ & $-0.38(1.96)$ & $0.813^{a}$ \\
\hline MFIS & $\mathrm{n}=18$ & $\mathrm{n}=19$ & \\
\hline Mean & $38.89(21.65)$ & $34.11(13.59)$ & $0.412^{a}$ \\
\hline Change from baseline & $-3.76(12.63)$ & $2.06(12.11)$ & $0.178^{a}$ \\
\hline BDI & $n=18$ & $\mathrm{n}=18$ & \\
\hline Mean & $9.78(7.37)$ & $9.00(6.37)$ & $0.820^{a}$ \\
\hline Change from baseline & $0.13(4.98)$ & $0.41(5.17)$ & $0.610^{\mathrm{a}}$ \\
\hline \multicolumn{4}{|c|}{$\begin{array}{l}\text { Abbreviations: BDI = Beck Depression Inventory; EDSS = Expanded Disability Status Scale; EGCG = epigallocatechin-3-gallate; FSS = Fatigue Severity Scale; MFIS } \\
=\text { Modified Fatigue Impact Scale. } \\
\text { Data are mean (SD), number (\%) or median (range). } \\
\text { a Exact Mann-Whitney test. } \\
\text { b Exact } \chi^{2} \text { test. }\end{array}$} \\
\hline
\end{tabular}

(difference $0.08 \%$ ), $\mathrm{T} 2 \mathrm{w}$ lesion count and volume, and in CELs (table 1).

\section{Clinical Outcomes}

When evaluating clinical end points (table 2), we found no difference between groups in EDSS, CDP, the mean change in EDSS between baseline and at month 36, MSFC and its subscores, and BDI as well as fatigue scores. Eighteen of 27 patients (66.67\%) in the EGCG and 20/28 patients (71.43\%) in the placebo group were relapse free during the study. The ARR until month 36 and CDP were similar in both groups. There was no difference between EGCG and placebo in the ARR between baseline and month 18 and between months 18 and 36 (data not shown). 
A

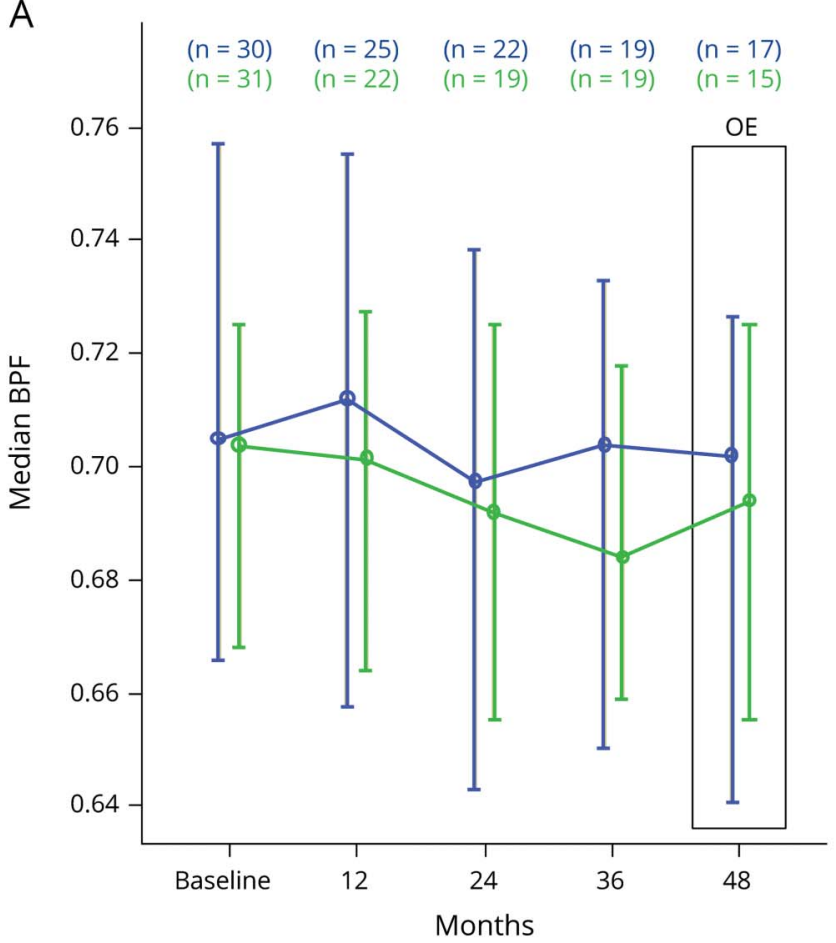

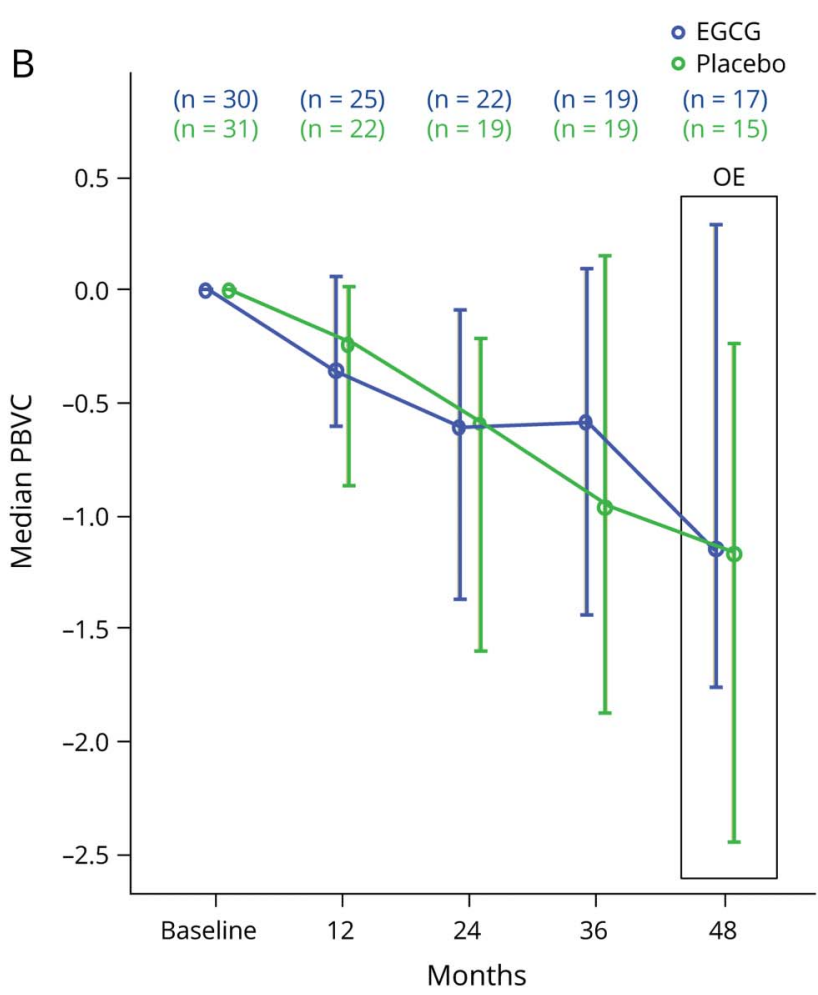

(A) Primary outcome: brain parenchymal fraction; only a significant effect of time was observed $(p<0.001)$, no group difference $(p=0.520)$ and no interaction $(p=0.647)$. (B) Secondary outcome: percentage brain volume change; significant effect of time $(p<0.001)$, no group difference $(p=00.476)$, and no interaction $(p=0.807)$. Bars represent $25 \%-75 \%$ quartiles. EGCG = epigallocatechin-3-gallate; OE = open-label extension.

The results of the PP analyses concerning primary and all secondary outcome parameters did not differ from those of the PAS analyses (data not shown).

\section{Subgroup Analyses}

In performed subgroup analyses for patients with lower and higher $\mathrm{BPF}$ ( $\leq$ median BPF vs $>$ median BPF at baseline) and for patients with and without CEL during the study, the change in brain atrophy was not significantly different between groups. Also in subgroups with clinically milder disease (EDSS score $<5$ ) and in patients with lower Individual Progression Index (EDSS/years of symptoms), we could not detect a difference for the primary end point.

Furthermore, no sex effects were found relating to PBVC, $\mathrm{BPF}$, and EDSS.

\section{Longitudinal Analyses}

Longitudinal analyses of the entire time course ${ }^{25}$ including all available time points $(0,12,24$, and 36 months) also showed no difference in MRI and clinical parameters for the primary and secondary end points. These findings were confirmed by longitudinal covariance analyses ${ }^{24}$ (see multivariate longitudinal analysis for brain atrophy in figure 2 and T2w lesions in figure 3 ).

\section{Safety}

Of the 30 participants in the EGCG group 29 (96.7\%) and of the 31 participants in the placebo group, 28 (90.3\%) experienced 1 or more AEs. Eleven (36.7\%) in the EGCG and $10(32.3 \%)$ in the placebo group had a serious adverse event (SAE). None of the SAEs were considered related to the study drug. All occurred due to hospitalization of study participants for various reasons (table e-2, links.lww.com/NXI/A420).

The incidence of SAEs and AEs was similar in both study groups. The most common AEs (>3\%) were flu-like infections, urinary tract infections, fractures and contusions after falling, and elevated liver enzymes, without statistical difference between groups.

\section{Open-Label Extension}

Seventeen patients from the EGCG group and 15 patients from the former placebo group were available for follow-up assessments at the end of OE. At month 48, there were no significant differences in BPF (BPF former EGCG $=0.6911$, BPF former placebo group $=0.6879 ; p=0.860$ ). PBVC and clinical progression parameters (EDSS, MSFC, and subscales) showed no significant difference between former groups and to the randomized phase of the study (data of the OE not shown).

During OE, AEs and SAEs were similar to the randomized phase, especially no elevation of liver enzymes or other hepatotoxic side effects occurred. However, 2 patients reported intolerability of study medication and decided to stop treatment. 

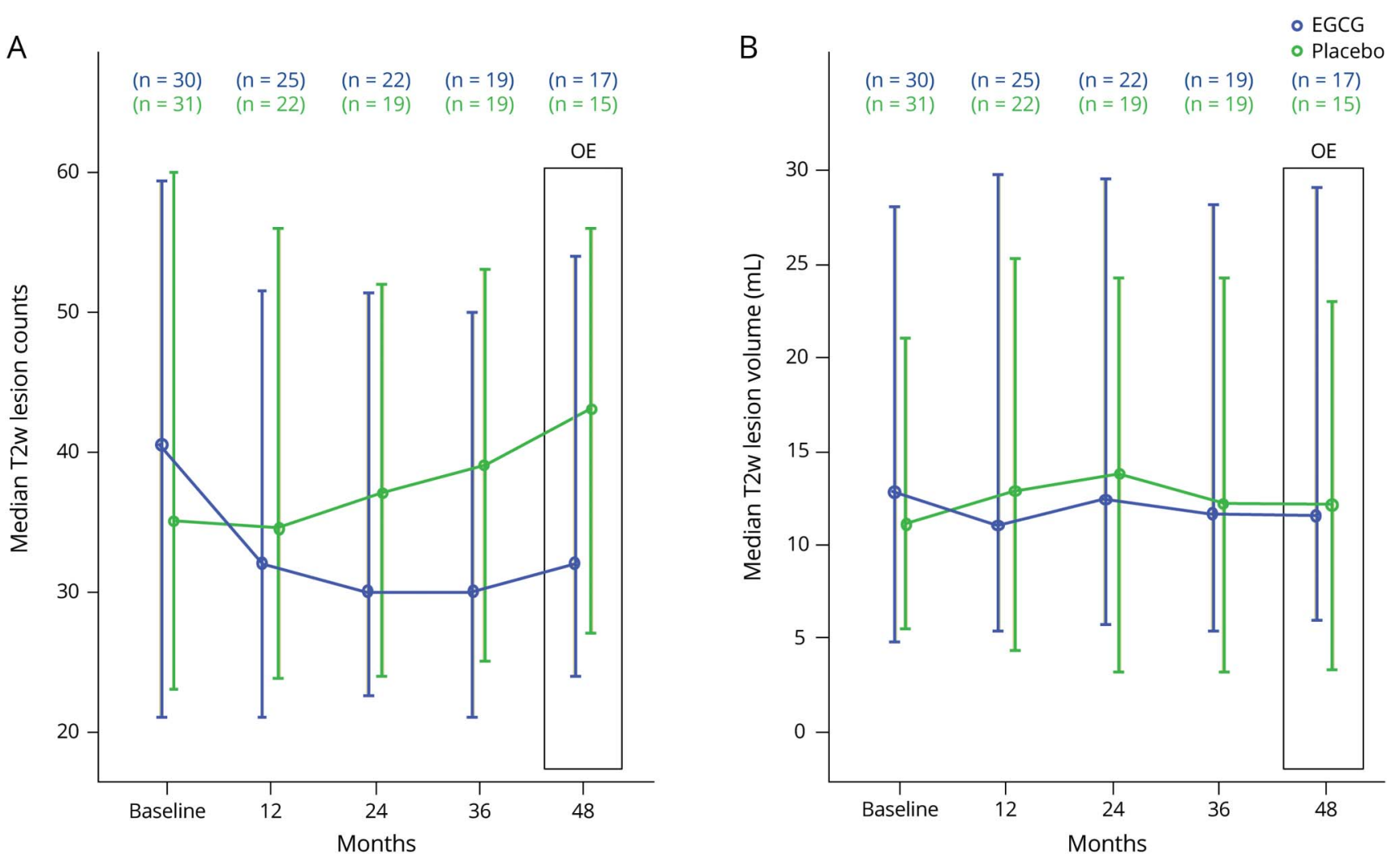

(A) Secondary outcome: median T2w lesion counts; a significant effect of time was observed $(p<0.001)$, no group difference $(p=0.582)$ and no interaction $(p=$ 0.417). (B) Secondary outcome: median T2w lesion volume in $\mathrm{mL}$; significant effect of time $(p<0.001)$, no group difference $(p=0.821)$, and no interaction $(p=$ 0.324). Bars represent $25 \%-75 \%$ quartiles. EGCG = epigallocatechin gallate; $\mathrm{OE}=$ open-label extension.

\section{Discussion}

This randomized, placebo-controlled trial failed to show an effect of oral EGCG on radiographic (brain atrophy, T2w lesions) and clinical (EDSS, relapses, and MSFC) disease progression in patients with SPMS or PPMS. These results challenge preclinical data suggesting a neuroprotective and anti-inflammatory capacity of EGCG in an animal study with $\mathrm{EAE}^{10}$ where it was shown that orally applied EGCG decreased $\mathrm{T}$-cell proliferation and $\mathrm{TNF} \alpha$ production of encephalitogenic T-cells via suppression of NF-kB activation and inhibited neuronal cell death by interference with reactive oxygen species formation. These findings provided the rationale for putative antioxidant and anti-inflammatory effects of EGCG also in human CNS. However, our results are in line with a study on EGCG in multiple system atrophy ${ }^{27}$ and another study from our group that did not find an effect of oral EGCG on T2w lesion evolution, PBVC, and clinical disease measures in patients with relapsing-remitting MS (RRMS). ${ }^{28}$

A key issue of the negative outcome of our study seems to be the small sample size of the study. With only 61 patients included and a dropout rate of more than $30 \%$ (mostly due to personal reasons and less to side effects), our study was underpowered and the effect size was overestimated from the beginning as we have learned meanwhile. ${ }^{29} \mathrm{~A}$ post hoc power calculation revealed a number of 1936 patients per group needed to detect the given effect size $=0.092$ with a power of $80 \%$ and a type 1 error ( $\alpha$ ) of 5\% ( 2 sided). With the 19 patients per group of our specific cohort, it would only be possible to detect a high effect size $=1.00$.

Even in the recently published MS-SMART Study, investigating the effects of 3 different neuroprotective substances with about 100 patients per group, no difference in PBVC could be detected. ${ }^{30}$

Our cohort was a representative population of patients with PMS, including a large proportion of patients who were in a nonrelapsing stage of PMS and had a high level of established disability with a median EDSS score of 6.0 at study entry. Nevertheless, we unexpectedly detected a nonpathologic annual PBVC rate (0.2-0.3\% per year) in our study population in comparison to various other PMS trials examining the effect of fingolimod, ${ }^{31}$ siponimod, ${ }^{5}$ lamotrigine, ${ }^{32}$ ocrelizumab, ${ }^{4}$ or natalizumab, ${ }^{33}$ reporting an annual atrophy rate of $0.4-0.7 \%$, disregarding the verum and placebo group. Only 2 studies with PMS reported a similarly low atrophy rate (ibudilast $^{6}$ and simvastatin/verum $\operatorname{arm}^{34}$ ). The possibility to prove a positive effect of an intervention depends on adequate 
dynamics of the investigated variable. Therefore, we may speculate that our study population was too stable to detect a beneficial effect on radiographic disease progression markers.

Another possible reason for the negative outcome seems to be the insufficient bioavailability of oral EGCG in the doses used in these studies. ${ }^{35}$ Previous studies had reported doses of up to $800 \mathrm{mg}$ EGCG per day as safe and generally well tolerated, e.g., in healthy volunteers, where the plasma elimination halflife of EGCG was measured to be about 5 hours after repeated administration of $800 \mathrm{mg}$ EGCG daily over 10 days. ${ }^{36}$ Therefore, we chose a maximum daily dose of $800 \mathrm{mg}$ EGCG until month 30 , a maximum daily dose of $1,200 \mathrm{mg}$ until month 36, and for the optional OE until month 48. Evidence was found that $600 \mathrm{mg}$ EGCG beneficially influences muscle metabolism in patients with $\mathrm{MS}^{11}$; however, our dosages were not sufficient to achieve an effect in the CNS. Recently, a new study proposed the bioavailability of EGCG to be less than $1 \%$ in humans from ingestion, with a clearance from the systemic circulation within a few hours. ${ }^{7}$ Although we did not measure plasma levels of EGCG in this study, our previous study in RRMS showed that plasma levels of EGCG are extremely variable across patients despite equal dosing. ${ }^{28}$ Moreover, although passage of EGCG through the blood-brain barrier (BBB) was shown in animal studies, ${ }^{7}$ proof of CNS entry of EGCG in humans is lacking.

In comparison to, e.g., the ocrelizumab ORATORIO trial (baseline: median EDSS score 4.5), the disease duration and the EDSS were higher in our study. Furthermore, active progression just before study entry was not mandatory for our trial. The nature of the EDSS as an ordinal scale results in scores that are unequally distributed, and the individuals remain at a step in the scale for different lengths of time, especially at higher EDSS scores despite progressive disability. ${ }^{37}$ The considerations may explain why in a clinically stable cohort with high disability levels, subtle positive effects of EGCG at certain EDSS levels could not be demonstrated.

Although hepatotoxicity has been discussed as a potentially severe side effect of green tea dietary supplements ${ }^{13}$ and Polyphenon, ${ }^{38}$ we did not observe any related SAE with our EGCG dosing regimen. In our study, only 1 subject dropped out due to elevated liver enzymes. Also, in our study on EGCG in RRMS, no relevant liver toxicity occurred. ${ }^{28} \mathrm{~A}$ possible explanation could be that pure EGCG is less harmful than GTE or Polyphenon regarding hepatotoxicity. GTE and Polyphenon contain several types of polyphenols. However, in the PROMESA study, 8 of 47 patients treated with EGCG up to a maximum dose of $1,200 \mathrm{mg}$ for up to 40 weeks ( 48 weeks in total including the dosage phase) experienced hepatotoxicity. This was determined as increased aminotransferase concentrations of which 2 were regarded as SAEs (aminotransferase concentrations greater than 5 times the upper limit). ${ }^{27}$ The concomitant medication with among others levodopa (which itself may cause elevated liver enzymes) and the mean age of the patients being 10 years older than in the MS studies (possibly leading to more concomitant diseases) may be an explanation for worse tolerability.

Recent studies reported beneficial effects of orally applied EGCG on cognitive functions in combination with cognitive training in patients with Down syndrome and fragile $\mathrm{X}$ syndrome. ${ }^{39,40}$ Our study also found an improvement of the PASAT score in both study groups, favoring EGCG (change from baseline: EGCG 3.82 [SD 9.65], placebo 1.00 [SD 5.79]; $p$ value $=0.051$ ). The PASAT measures cognitive function such as calculation ability, auditory information processing speed, and flexibility. These findings may suggest that EGCG could have a positive effect on the cognitive functions of patients with PMS. Training effects of the PASAT due to 3 test scorings before the study are unlikely. However, this result should be interpreted carefully because it was observed as a statistical trend and our study was not designed to evaluate this outcome specifically.

EGCG at a dose of up to 1,200 mg daily was overall safe and well tolerated in patients with PMS over a period of 36 months and a 12-month open-label extension. However, we did not find an effect of treatment on MRI or clinical disease activity parameters. Possible explanations include the small sample size and the high dropout rate. First indications were found that EGCG treatment may beneficially affect cognitive functions also in MS. Thus, further investigation in larger MS cohorts may be warranted, especially for improvement of cognitive functions with adjuvant treatment. Such studies should consider using optimized formulations of EGCG for increased bioavailability and ideally with proven $\mathrm{BBB}$ passage.

\section{Acknowledgment}

The authors are very grateful to all their patients who participated in this trial. They thank Susan Pikol and Cynthia Kraut for technical MRI assistance and Bibiane Seeger for laboratory measurements. They are thankful to Taiyo International for providing them with the investigational product (Sunphenon powder) free of charge.

\section{Study Funding}

The authors report no targeted funding.

\section{Disclosure}

R. Rust reports speaking fees from Roche, unrelated to this study; J. Wuerfel reports no conflict in respect to this work; he is employee of MIAC AG, Basel, Switzerland; he participated in advisory boards (Biogen, Idorsia, Novartis, Roche, and Sanofi) and is supported by the EU (Horizon2020). J. Doerr reports research support from Bayer and Novartis, honoraria for lectures and advisory from Bayer, Novartis, Sanofi Aventis, Merck Serono, Biogen, and Roche, and travel support from Bayer, Novartis, Biogen, and Merck Serono. H.G. Zimmermann received research grants from Novartis and speaking fees from Bayer, unrelated to this study. A.U. Brandt is cofounder and shareholder of technology startups Motognosis $\mathrm{GmbH}$ and Nocturne $\mathrm{GmbH}$; he is named as inventor on 
several patent applications describing serum biomarkers for multiple sclerosis, perceptive computing for motor symptoms and retinal image analysis using optical coherence tomography. J. Bellmann-Strobl reports nonfinancial support from Bayer HealthCare, grants from Biogen Idec and Merck Serono, and personal fees from Teva $\mathrm{GmbH}$, Sanofi Genzyme, Roche, and Novartis, outside the submitted work. F. Paul reports nonfinancial support from Taiyo International, grants from Teva $\mathrm{GmbH}$, and other from the German Research Council (DFG), during the conduct of the study; he serves on scientific advisory boards of Novartis OCTIMS study steering committee and MedImmune/Viela Bio steering committee; he received funding for travel or speaker honoraria from Bayer, Novartis, Biogen Idec, Teva, Sanofi Aventis/ Genzyme, Merck Serono, Alexion, Chugai, MedImmune, Shire, Roche, Actelion, and Celgene and serves on editorial boards of PLoS One (academic editor) and Neurology Neuroimmunology and Neuroinflammation (Associate Editor); he provided consultancies for Sanofi Genzyme, Biogen Idec, MedImmune, Shire, and Alexion; he received research support from Bayer, Novartis, Biogen Idec, Teva, Sanofi-Aventis/Genzyme, Alexion, and Merck. Go to Neurology.org/NN for full disclosures.

\section{Publication History}

Received by Neurology: Neuroimmunology \& Neuroinflammation September 15, 2020. Accepted in final form December 17, 2020.

Appendix Authors

\begin{tabular}{lll}
\hline Name & Location & Contribution \\
\hline $\begin{array}{l}\text { Rebekka Rust, } \\
\text { MD }\end{array}$ & $\begin{array}{ll}\text { Charité-Universitätsmedizin, } \\
\text { Berlin, Berlin, Germany }\end{array}$ & $\begin{array}{l}\text { Analyzed and } \\
\text { interpreted the data } \\
\text { and drafted the } \\
\text { manuscript for } \\
\text { intellectual content }\end{array}$ \\
\hline $\begin{array}{ll}\text { Claudia Chien, } \\
\text { MSc }\end{array}$ & Charité-Universitätsmedizin & $\begin{array}{l}\text { Analyzed and } \\
\text { interpreted the data } \\
\text { and revised the } \\
\text { manuscript for }\end{array}$ \\
& & $\begin{array}{l}\text { merlin, Germany } \\
\text { intellectual content }\end{array}$ \\
\end{tabular}

Michael Charité-Universitätsmedizin Analyzed the data and

Scheel, MD Berlin, Berlin, Germany revised the manuscript for intellectual content

\begin{tabular}{lll}
\hline $\begin{array}{l}\text { Alexander U. } \\
\text { Brandt, MD }\end{array}$ & Charité-Universitätsmedizin & Major role in the \\
& Berlin, Berlin, Germany & $\begin{array}{l}\text { acquisition of data } \\
\text { and revised the } \\
\text { manuscript for } \\
\end{array}$ \\
& intellectual content
\end{tabular}

Jan Dörr, MD Charité-Universitätsmedizin Designed and
Berlin, Berlin, Germany conceptualized the study; major role in the acquisition of data; and revised the manuscript for intellectual content

\begin{tabular}{ll}
\hline Jens Würfel, & $\begin{array}{l}\text { University Basel, Basel, } \\
\text { Switzerland }\end{array}$ \\
& $\begin{array}{l}\text { Designed and } \\
\text { conceptualized the } \\
\text { study and revised the } \\
\text { manuscript for } \\
\text { intellectual content }\end{array}$ \\
\end{tabular}

Appendix (continued)

\begin{tabular}{|c|c|c|}
\hline Name & Location & Contribution \\
\hline $\begin{array}{l}\text { Katharina } \\
\text { Klumbies, MD }\end{array}$ & $\begin{array}{l}\text { Charité-Universitätsmedizin } \\
\text { Berlin, Berlin, Germany }\end{array}$ & $\begin{array}{l}\text { Major role in the } \\
\text { acquisition of data; } \\
\text { analyzed the data; } \\
\text { and revised the } \\
\text { manuscript for } \\
\text { intellectual content }\end{array}$ \\
\hline $\begin{array}{l}\text { Hanna G. } \\
\text { Zimmermann, } \\
\text { PhD }\end{array}$ & $\begin{array}{l}\text { Charité-Universitätsmedizin } \\
\text { Berlin, Berlin, Germany }\end{array}$ & $\begin{array}{l}\text { Major role in the } \\
\text { acquisition of data; } \\
\text { analyzed the data; } \\
\text { and revised the } \\
\text { manuscript for } \\
\text { intellectual content }\end{array}$ \\
\hline $\begin{array}{l}\text { Mario Lorenz, } \\
\text { PhD }\end{array}$ & $\begin{array}{l}\text { Charité-Universitätsmedizin } \\
\text { Berlin, Berlin, Germany }\end{array}$ & $\begin{array}{l}\text { Interpreted the data } \\
\text { and revised the } \\
\text { manuscript for } \\
\text { intellectual content }\end{array}$ \\
\hline $\begin{array}{l}\text { Klaus-Dieter } \\
\text { Wernecke, } \\
\text { PhD }\end{array}$ & $\begin{array}{l}\text { Charité-Universitätsmedizin } \\
\text { Berlin, Berlin, Germany }\end{array}$ & $\begin{array}{l}\text { Analyzed the data and } \\
\text { drafted the } \\
\text { manuscript for } \\
\text { intellectual content }\end{array}$ \\
\hline $\begin{array}{l}\text { Judith } \\
\text { Bellmann- } \\
\text { Strobl, MD }\end{array}$ & $\begin{array}{l}\text { Charité-Universitätsmedizin } \\
\text { Berlin, Berlin, Germany }\end{array}$ & $\begin{array}{l}\text { Major role in the } \\
\text { acquisition of data; } \\
\text { analyzed and } \\
\text { interpreted the data; } \\
\text { and drafted the } \\
\text { manuscript for } \\
\text { intellectual content }\end{array}$ \\
\hline $\begin{array}{l}\text { Friedemann } \\
\text { Paul, MD }\end{array}$ & $\begin{array}{l}\text { Charité-Universitätsmedizin } \\
\text { Berlin, Berlin, Germany }\end{array}$ & $\begin{array}{l}\text { Designed and } \\
\text { conceptualized the } \\
\text { study; major role in } \\
\text { the acquisition of } \\
\text { data; analyzed and } \\
\text { interpreted the data; } \\
\text { and revised the } \\
\text { manuscript for } \\
\text { intellectual content }\end{array}$ \\
\hline
\end{tabular}

\section{References}

1. Fazekas F. Where to go next with neuroprotection in multiple sclerosis? Lancet Neurol 2010;9:647-648.

2. Reich DS, Lucchinetti CF, Calabresi PA. Multiple sclerosis N Engl J Med 2018;378: 169-180.

3. Fiol MP, Ysrraelit MC, Gaitán MI, Correale J. Progressive multiple sclerosis: from pathogenic mechanisms to treatment. Brain 2016;140:527-546.

4. Montalban X, Hauser SL, Kappos L, et al. Ocrelizumab versus placebo in primary progressive multiple sclerosis. N Engl J Med 2017;376:209-220.

5. Kappos L, Bar-Or A, Cree BAC, et al. Siponimod versus placebo in secondary progressive multiple sclerosis (EXPAND): a double-blind, randomised, phase 3 study. Lancet 2018;391:1263-1273.

6. Chen JE, Glover GH. Phase 2 trial of ibudilast in progressive multiple sclerosis. N Engl J Med 2016;25:289-313.

7. Pervin M, Unno K, Takagaki A, Isemura M, Nakamura Y. Function of green tea catechins in the brain: epigallocatechin gallate and its metabolites. Int J Mol Sci 2019;20:1-12.

8. Wang J, Ren Z, Xu Y, Xiao S, Meydani SN, Wu D. Epigallocatechin-3-gallate ameliorates experimental autoimmune encephalomyelitis by altering balance among CD4+ T-cell subsets. Am J Pathol 2012;180:221-234.

9. Lorenz M, Paul F, Moobed M, et al. The activity of catechol-O-methyltransferase (COMT) is not impaired by high doses of epigallocatechin-3-gallate (EGCG) in vivo. Eur J Pharmacol 2014;740:645-651.

10. Aktas O, Prozorovski T, Smorodchenko A, et al. Green tea epigallocatechin-3-gallate mediates T cellular NF- B inhibition and exerts neuroprotection in autoimmune encephalomyelitis. J Immunol J Immunol 2004:173:5794-5800.

11. Mähler A, Steiniger J, Bock M, et al. Metabolic response to epigallocatechin-3-gallate in relapsingremitting multiple sclerosis: a randomized clinical trial. Am J Clin Nutr 2015;101:487-495.

12. Mähler A, Mandel S, Lorenz M, et al. Epigallocatechin-3-gallate: a useful, effective and safe clinical approach for targeted prevention and individualised treatment of neurological diseases? EPMA J 2013;4:5.

13. Dekant W, Fujii K, Shibata E, Morita O, Shimotoyodome A. Safety assessment of green tea based beverages and dried green tea extracts as nutritional supplements. Toxicol Lett 2017;277:104-108. 
14. Polman $\mathrm{CH}$, Reingold SC, Edan G, et al. Diagnostic criteria for multiple sclerosis: 2005 revisions to the "McDonald criteria." Ann Neurol 2005;58:840-846.

15. Kurtzke JF. On the origin of EDSS. Mult Scler Relat Disord 2015;4:95-103.

16. Cohen JA, Reingold SC, Polman CH, Wolinsky JS. Disability outcome measures in multiple sclerosis clinical trials: current status and future prospects. Lancet Neurol 2012;11:467-476.

17. Fischer JS, Rudick RA, Cutter GR, Reingold SC. The multiple sclerosis functional composite measure (MSFC): an integrated approach to MS clinical outcome assessment. Mult Scler J 1999;5:244-250.

18. Krupp LB, Larocca NG, Muir Nash J, Steinberg AD. The fatigue severity scale: application to patients with multiple sclerosis and systemic lupus erythematosus. Arch Neurol 1989;46:1121-1123.

19. Fisk JD, Ritvo PG, Ross L, Haase DA, Marrie TJ, Schlech WF. Measuring the functional impact of fatigue: initial validation of the fatigue impact scale. Clin Infect Dis 1994;18:S79-S83.

20. Beck AT, Ward CH, Mendelson M, Mock J, Erbaugh J. An inventory for measuring depression. Arch Gen Psychiatry 1961;4:561-571.

21. Smith SM, Zhang Y, Jenkinson M, et al. Accurate, robust, and automated longitudinal and cross-sectional brain change analysis. Neuroimage 2002;17:479-489.

22. Yushkevich PA, Piven J, Hazlett HC, et al. User-guided 3D active contour segmentation of anatomical structures: significantly improved efficiency and reliability. Neuroimage 2006;31:1116-1128.

23. Kalkers NF, Ameziane N, Bot JCJ, Minneboo A, Polman CH, Barkhof F. Longitudinal brain volume measurement in multiple sclerosis: rate of brain atrophy is independent of the disease subtype. Arch Neurol 2002;59:1572-1576.

24. Friede T, Kieser M. Sample size recalculation in internal pilot study designs: a review. Biom J 2006;48:537-555.

25. Brunner E, Domhof S, Langer F. Nonparametric Analysis of Longitudinal Data in Factorial Experiments. J. Wiley; 2002. Available at: books.google.de/books?id=UxzvAAAAMAAJ.

26. Bathke A, Brunner E. A nonparametric alternative to analysis of covariance. In: Akritas MG, Politis DN, eds. Recent Advances and Trends in Nonparametric Statistics. Amsterdam, the Netherlands: Elsevier BV; 2003:109-120.

27. Levin J, Maaß S, Schuberth M, et al. Safety and efficacy of epigallocatechin gallate in multiple system atrophy (PROMESA): a randomised, double-blind, placebocontrolled trial. Lancet Neurol 2019;18:724-735.

28. Bellmann-Strobl J, Paul F, Wuerfel J, et al. Epigallocatechin-gallate in relapsing remitting MS: a randomized, double-blind, placebo-controlled trial. Neurol Neuroimmunol Neuroinflamm 2021;8:e981. doi: 10.1212/NXI.0000000000000981.
29. Altmann DR, Jasperse B, Barkhof F, et al. Sample sizes for brain atrophy outcomes in trials for secondary progressive multiple sclerosis. Neurology 2009;72:595601.

30. Chataway J, De Angelis F, Connick P, et al. Efficacy of three neuroprotective drugs in secondary progressive multiple sclerosis (MS-SMART): a phase $2 \mathrm{~b}$, multiarm, double-blind, randomised placebo-controlled trial. Lancet Neurol 2020;19:214-225.

31. Lublin F, Miller DH, Freedman MS, et al. Oral fingolimod in primary progressive multiple sclerosis (INFORMS): a phase 3, randomised, double-blind, placebocontrolled trial. Lancet 2016;387:1075-1084.

32. Kapoor R, Furby J, Hayton T, et al. Lamotrigine for neuroprotection in secondary progressive multiple sclerosis: a randomised, double-blind, placebo-controlled, parallel-group trial. Lancet Neurol 2010;9:681-688.

33. Kapoor R, Ho PR, Campbell N, et al. Effect of natalizumab on disease progression in secondary progressive multiple sclerosis (ASCEND): a phase 3, randomised, doubleblind, placebo-controlled trial with an open-label extension. Lancet Neurol 2018;17: 405-415.

34. Chataway J, Schuerer N, Alsanousi A, et al. Effect of high-dose simvastatin on brain atrophy and disability in secondary progressive multiple sclerosis (MS-STAT): a randomised, placebo-controlled, phase 2 trial. Lancet 2014;383:2213-2221.

35. Chakrawarti L, Agrawal R, Dang S, Gupta S, Gabrani R. Therapeutic effects of EGCG: a patent review. Expert Opin Ther Pat 2016;26:907-916.

36. Ullmann U, Haller J, Decourt JD, Girault J, Spitzer V, Weber P. Plasma-kinetic characteristics of purified and isolated green tea catechin epigallocatechin gallate (EGCG) after 10 days repeated dosing in healthy volunteers. Int J Vitam Nutr Res 2004;74:269-278.

37. Ontaneda D, Thompson AJ, Fox RJ, Cohen JA. Progressive multiple sclerosis: prospects for disease therapy, repair, and restoration of function. Lancet 2017;389: $1357-1366$.

38. Lovera J, Ramos A, Devier D, et al. Polyphenon E, non-futile at neuroprotection in multiple sclerosis but unpredictably hepatotoxic: phase I single group and phase II randomized placebo-controlled studies. J Neurol Sci 2015;358:46-52.

39. de la Torre R, de Sola S, Hernandez G, et al. Safety and efficacy of cognitive training plus epigallocatechin-3-gallate in young adults with Down's syndrome (TESDAD): a double-blind, randomised, placebo-controlled, phase 2 trial. Lancet Neurol 2016;15: 801-810.

40. de la Torre R, de Sola S, Farré M, et al. A phase 1, randomized double-blind, placebo controlled trial to evaluate safety and efficacy of epigallocatechin-3-gallate and cognitive training in adults with fragile X syndrome. Clin Nutr 2020;39:378-387. 


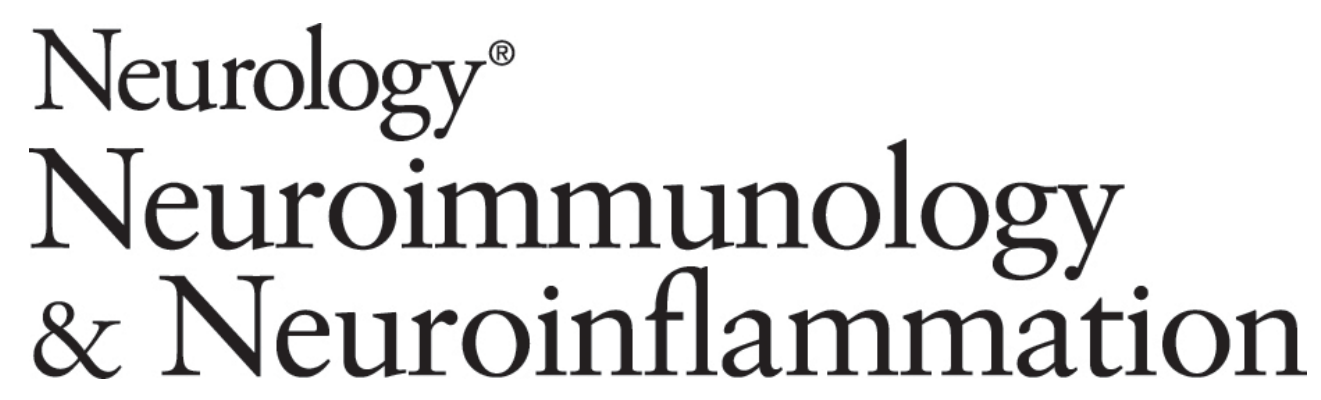

Epigallocatechin Gallate in Progressive MS: A Randomized, Placebo-Controlled Trial Rebekka Rust, Claudia Chien, Michael Scheel, et al.

Neurol Neuroimmunol Neuroinflamm 2021;8;

DOI 10.1212/NXI.0000000000000964

This information is current as of February 23, 2021

Neurol Neuroimmunol Neuroinflamm is an official journal of the American Academy of Neurology.

Published since April 2014, it is an open-access, online-only, continuous publication journal. Copyright

Copyright $\odot 2021$ The Author(s). Published by Wolters Kluwer Health, Inc. on behalf of the American

Academy of Neurology.. All rights reserved. Online ISSN: 2332-7812.

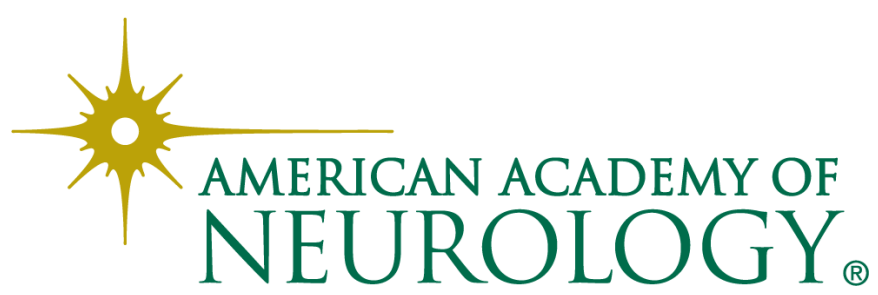




\section{Updated Information \& Services}

References

Citations

Subspecialty Collections

Permissions \& Licensing

Reprints including high resolution figures, can be found at: http://nn.neurology.org/content/8/3/e964.full.html

This article cites 37 articles, 1 of which you can access for free at: http://nn.neurology.org/content/8/3/e964.full.html\#\#ref-list-1

This article has been cited by 1 HighWire-hosted articles: http://nn.neurology.org/content/8/3/e964.full.html\#\#otherarticles

This article, along with others on similar topics, appears in the following collection(s):

Autoimmune diseases

http://nn.neurology.org//cgi/collection/autoimmune_diseases Class II

http://nn.neurology.org//cgi/collection/class_ii

Clinical trials Randomized controlled (CŌNSORT agreement)

http://nn.neurology.org//cgi/collection/clinical_trials_randomized_cont rolled_consort_agreement

MRI

http://nn.neurology.org//cgi/collection/mri

Multiple sclerosis

http://nn.neurology.org//cgi/collection/multiple_sclerosis

Information about reproducing this article in parts (figures,tables) or in its entirety can be found online at:

http://nn.neurology.org/misc/about.xhtml\#permissions

Information about ordering reprints can be found online:

http://nn.neurology.org/misc/addir.xhtml\#reprintsus

Neurol Neuroimmunol Neuroinflamm is an official journal of the American Academy of Neurology.

Published since April 2014, it is an open-access, online-only, continuous publication journal. Copyright

Copyright $\odot 2021$ The Author(s). Published by Wolters Kluwer Health, Inc. on behalf of the American

Academy of Neurology.. All rights reserved. Online ISSN: 2332-7812.

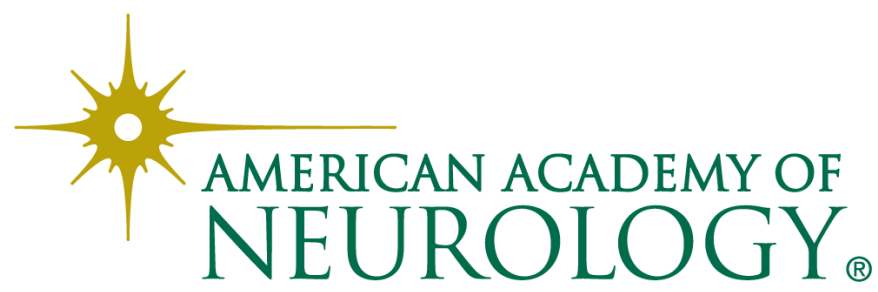

